\section{A meta-analytic investigation of the role of reward on inhibitory control}

\author{
Sam Burton (D, Graeme Knibb and Andrew Jones
}

Quarterly Journal of Experimental Psychology

2021, Vol. 74(10) 1818-1828

(c) Experimental Psychology Society 2021

\section{(c) (1)}

Article reuse guidelines:

sagepub.com/journals-permissions

DOI: 10.1 I $77 / 174702$ I82/ I008895

qjep.sagepub.com

(SSAGE

\begin{abstract}
Contemporary theories predict that inhibitory control (IC) can be improved when rewards are available for successfully inhibiting. In non-clinical samples empirical research has demonstrated some support; however, "null" findings have also been published. The aim of this meta-analysis was to clarify the magnitude of the effect of reward on IC and identify potential moderators. A total of 73 articles (contributing $k=80$ studies) were identified from PubMed, Psyclnfo, and Scopus, published between 1997 and 2020, using a systematic search strategy. A random effects meta-analysis was performed on effect sizes generated from IC tasks, which included rewarded and non-rewarded inhibition trials. Moderator analyses were conducted on clinical samples (vs "healthy controls"), task type (go/no-go vs stop signal vs Flanker vs Simon vs Stroop vs Anti-saccade), reward type (monetary vs points vs other), and age (adults vs children). The prospect of reward for successful inhibition significantly improved IC (SMD $=0.429,95 \% \mathrm{Cl}=0.288,0.570, I^{2}=96.7 \%$ ) compared with no reward conditions/groups. This finding was robust against influential cases and outliers. The significant effect was present across all IC tasks. There was no evidence of the effect moderated by type of reward, age, or clinical samples. Moderator analyses did not resolve the considerable heterogeneity. The findings suggest that IC is a transient state that fluctuates in response to motivations driven by reward. Future research might examine the potential of improving IC through rewards as a behavioural intervention.
\end{abstract}

\title{
Keywords
}

Motivation; reward; inhibitory control; stop signal; go/no-go

Received: 24 February 2020; revised: II March 202I; accepted: 19 March 202 I

\section{Introduction}

Inhibitory control (IC) is defined as "the (in)ability to change, suppress or delay a response that is no longer required under the current circumstances" (Logan et al., 1984 ) and is thought to be a core component of executive functioning and impulsive responding (Bickel et al., 2012). IC (also termed "response inhibition") can be both reactive and proactive (Braver et al., 2007). Reactive control refers to the act of stopping a response as a "late correction" mechanism, whereas proactive control is the preplanned behavioural alterations (e.g., response slowing) in anticipation of subsequent inhibition (Aron, 2011).

Computerised tasks have been developed for the assessment and operationalisation of IC in the laboratory settings, with the most common being the "stop signal" and "go/no-go (GNG) tasks." While these tasks measure slightly different forms of reactive IC (action cancellation vs action restraint; see Eagle et al., 2008), their component parts are similar. Both establish prepotent/dominant motor responses through promoting speeded reaction times to usually arbitrary cues. On a majority of trials, usually $75 \%$ or greater (Young et al., 2018), these responses are uninterrupted and thus prepotent or dominant responding is reinforced. However, on a minority of trials a "stop signal" or "no-go" cue is presented, prompting participants to withhold their prepotent motor response to the arbitrary cue. The inability to inhibit the prepotent response following presentation of the "stop signal" or "no-go" cue can be measured using commission errors (i.e., making a motor response to the arbitrary cue), or stop signal reaction time (SSRT: the unobserved latency of inhibition-see Band et al., 2003). Other tasks, such as the Stroop (1935) and Flanker tasks (Eriksen \& Eriksen, 1974), measure the

Psychological Sciences, University of Liverpool, Liverpool, UK

Corresponding author:

Sam Burton, Psychological Sciences, University of Liverpool, Liverpool L69 3BX, UK.

Email: S.P.Burton@liverpool.ac.uk 
ability to override responses to congruent stimuli but are used less frequently in the literature (Diamond, 2013).

The development of these computerised tasks has led to a proliferation of studies examining IC across numerous psychological characteristics and behavioural outcomes. For example, estimates suggest that $80 \%-90 \%$ of self-regulation attempts require some form of inhibition (Baumeister, 2014; Hofmann et al., 2012), highlighting a key role in behavioural adaptation and human survival (Verbruggen et al., 2014). Previous research has demonstrated that effective IC is associated with increased happiness and well-being (Hofmann et al., 2014), intelligence (Polderman et al., 2009), and psychosocial functioning (Anzman-Frasca et al., 2015); while poorer IC is associated with numerous maladaptive behaviours and outcomes such as alcohol dependence (Rubio et al., 2008), incidence of overweight/obesity (Blanco-Gómez et al., 2015), poor educational attainment (Caspi et al., 2016), and crime (Vazsonyi et al., 2017).

The majority of published research considers IC as a trait-like variable, stable within individuals over long periods. However, more recent research suggests that there are both internal and external factors which might cause transient changes in stopping responses (Jones et al., 2013; Keren \& Schul, 2009), which might better predict individual differences. For example, Berkman et al. (2017) propose that IC is a value-based process and represents a trade-off between short- and long-term rewards (Duckworth et al., 2016). This process involves assigning a momentary value for given behaviours, gains (e.g., money, or social approval), and costs (e.g., effort, and opportunity costs) to determine whether inhibition is required. Research has sought to enhance the "gains" valuation through the prospect of extrinsic or intrinsic rewards (Duckworth et al., 2018). This suggests that the role of motivation is key in the expression of IC processes (Poulton et al., 2016).

A number of studies have examined the role of motivation (through the prospect of obtaining rewards) on general cognitive performance, including reaction times, working memory, and task switching (Jimura et al., 2010; Umemoto \& Holroyd, 2015), all of which may have a downstream influence on inhibitory processes (Miyake \& Friedman, 2012; Snyder et al., 2015). Indeed, recent work has examined whether direct rewards for successful inhibition can improve IC. For example, Boehler et al. (2014) used a modified stop signal task (SST) in which the colour or the stop signal indicated whether inhibition would be rewarded or not. They demonstrated that on reward-related stop trials inhibition (measured using SSRT: the unobserved latency to inhibit behaviour) was greater than on reward-unrelated trials (see similar findings in Chiew et al., 2016; Geier \& Luna, 2012; Ma et al., 2016; and Schevernels et al., 2016). In a modified GNG task (the monetary incentive delay task; Demurie et al., 2016), participants were provided information at the beginning of each trial about the magnitude of monetary rewards available (No reward, Medium Reward, High Reward). Social, as well as monetary rewards, which consisted of positive feedback (e.g., "You're a champion" for high rewards) were also available. In this case, the effect of rewards did not influence the inhibition performance (see similar findings in Michałowski et al., 2017; Paschke et al., 2015; Schevernels et al., 2015; and Shanahan et al., 2008). Furthermore, some studies have reported the presence of reward being detrimental to IC (Marini et al., 2015; Williams et al., 2018; Yamaguchi \& Nishimura, 2019), possibly due to a break in attentional focus caused by reward stimuli (Wang et al., 2018). Finally, studies have examined whether the presence or magnitude of reward interacts with clinical diagnoses (e.g., attention-deficit hyperactivity disorder [ADHD], substance use disorder [SUD]); however, these effects are also equivocal (Charles-Walsh et al., 2016; Chung et al., 2011; Rosell-Negre et al., 2016).

Given the considerable amount of research in the area and the inconsistent pattern of findings across individual studies, our aim was to conduct a meta-analysis on the effects of reward on IC to clarify the magnitude of effect. We also aimed to examine potential moderators of the effect, including type of task used (stop signal, GNG, Antisaccade, Flanker, Simon, or Stroop), type of reward (monetary, points, or other), clinical samples versus non-clinical samples, and age (adults, children), in an attempt to explain potential heterogeneity of published findings. We hypothesised that the presence of rewards during IC tasks would improve subsequent IC. We did not make any directional hypotheses in regard to moderators. This meta-analysis was pre-registered on the Open Science Framework (see https://osf.io/5hbqu/) following the development of our systematic search terms, but prior to formal searches being carried out.

\section{Method}

\section{Search strategy}

We searched three electronic databases: Scopus, PubMed, and PsycInfo in September 2018. Searches were updated in December 2020. The following search terms were used: (1) response inhibition OR inhibitory control OR disinhibition OR, (2) stop signal OR stroop OR go/no* OR flanker OR Anti-saccade OR simon task, as well as (3) reward OR incentive*. Searches were limited to human participants, published in English, and between years 1978 and 2020. The reference list of each identified paper was examined for any eligible articles not identified through our search strategy, and this led to the addition of one further article (Asci et al., 2019).

\section{Eligibility criteria}

Studies were eligible for the meta-analysis when the following criteria were met. First, the study had to include a 


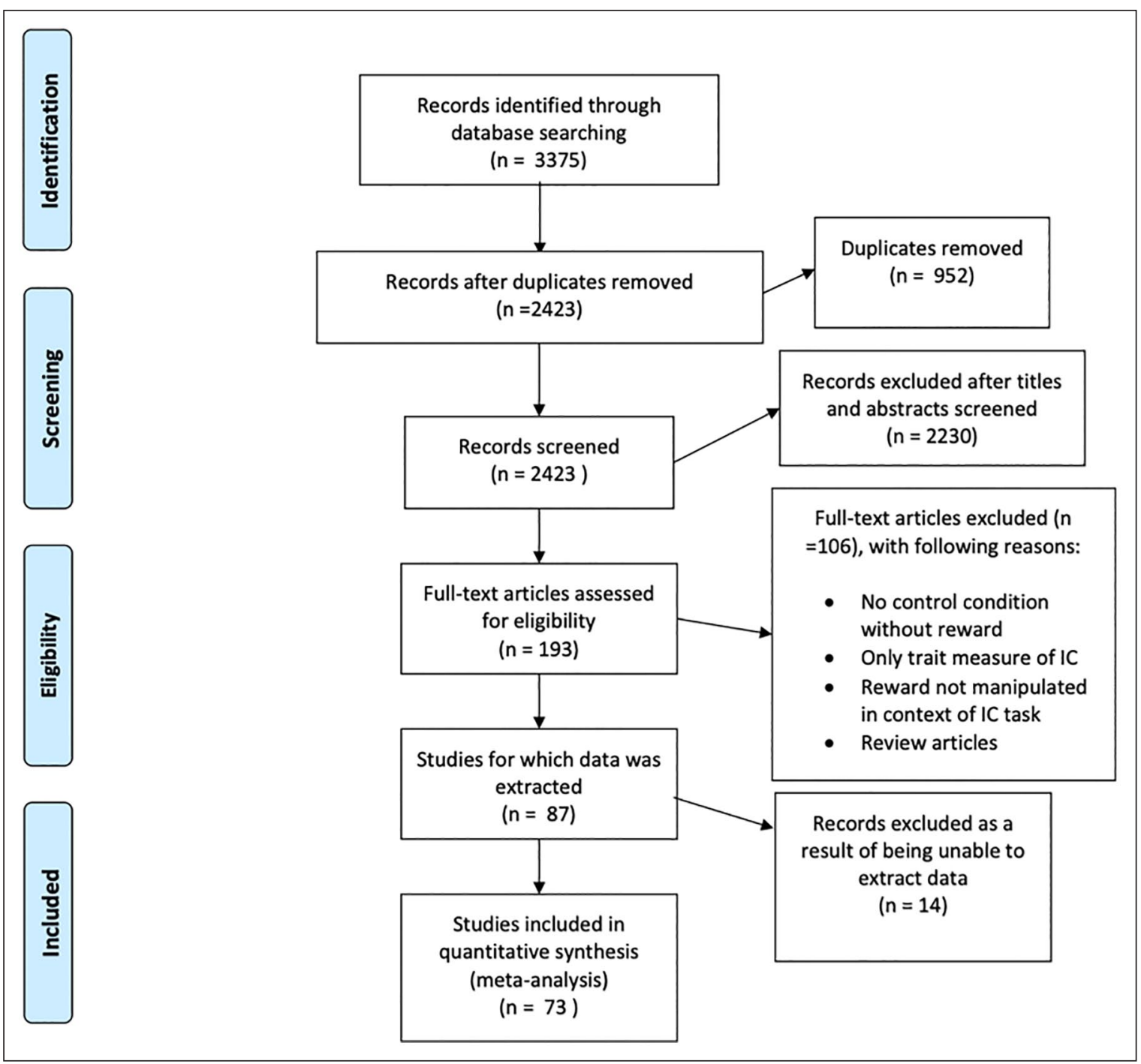

Figure I. PRISMA diagram of systematic search results.

validated behavioural measure of IC (outlined in Diamond, 2013), either SST, Stroop, GNG, Flanker, Anti-saccade, or Simon task. Second, the presence of reward for inhibitory performance (e.g., commission errors, SSRT, incongruent trials) was manipulated, for example, some inhibition/ incongruent was rewarded, and others were not. Studies were excluded if there was a reward condition without a control (no reward condition).

\section{Data extraction and coding}

The searches yielded a total of 2,422 unique papers, an additional paper was added following reference list searches of the included articles. Titles and abstracts of these papers were examined in relation to inclusion criteria, resulting in 193 articles that were eligible for a full-text screening. Following full-text screening, 87 articles were eligible for data extraction to be used for the meta-analysis, 14 studies $(16.09 \%)$ were excluded due to no reply to data requests, and 73 articles (80 effect sizes) were included. See the online supplementary material for the full table of studies included. The PRISMA flowchart can be seen in Figure 1.

\section{Coding of studies}

S.B. and G.K. coded and extracted all 73 articles; this included sample characteristics (gender distribution, age, clinical diagnosis), methodological information (measure of IC, reward manipulation), moderator information, and IC outcome (mean RT/error rate/accuracy rate for reward and no reward condition). For the SST we extracted SSRTs; for GNG tasks we extracted error/accuracy rates; for Antisaccade we extracted error/accuracy rates; and for the Stroop, Simon, and Flanker tasks we used incongruent RTs (as Prinzmetal et al. (2005) demonstrate, an increased sensitivity for RTs in cue-driven tasks).

Studies were coded as either adult samples, aged 18 years and above, or child samples if participants were 
younger than 18 years old. We examined whether studies recruited a clinical sample (e.g., ADHD, SUD, and autism spectrum disorder: see Table 1 in the supplementary material), versus "healthy controls." Given the heterogeneity in clinical samples, we also conducted separate analyses on ADHD samples versus healthy controls, and SUD samples versus healthy controls separately.

For full-text screening, there was near-perfect agreement between reviewers (Cohen's $k=0.95, p<.01$ ) and substantial agreement for the data extraction stage (Cohen's $k=.73, p<.01)$. Any disagreements were resolved by A.J. Information about each study is presented in Table 1 in the supplementary material.

Data analysis. We calculated the standardised mean difference $\left(\mathrm{SMD}=M^{\text {REWARD }}-M^{\text {NON-REWARD }} / S D^{\text {POOLED }}\right)$ and the standard error $(S E)$ of this difference, to conduct a random effects meta-analysis in "metafor" for R. We used the SMD to ensure different outcome measures used by different IC tasks and articles were comparable. For within subjects designs (e.g., Michałowski et al., 2017; Schevernels et al., 2016; Shanahan et al., 2008) the $S E$ was adjusted using the correlation between the reward and control outcome (in line with the Cochrane recommendations $\left(S E(\mathrm{SMD})=\sqrt{ }(1 / \mathrm{N})+\left(\mathrm{SMD}^{2} / 2 \mathrm{~N}\right) \times \sqrt{ } 2(1-\right.$ correlation $)$ (Cumpston et al., 2019). As the correlations between inhibition indices (reward and non-reward) were not readily available, we chose a correlation of .70, as recommended by previous research (Khoury et al., 2015; Rosenthal, 1991). However, we also conducted sensitivity analysis using coefficients of 0.50 and 0.90 . Outliers were identified by standardising the effect sizes and examining any extreme values at a $<.001(Z$ score $= \pm 3.30)$, and examining whether $95 \%$ confidence intervals did not overlap those from any other effect size. We examined potential biases in the evidence base (e.g., publication bias) using Egger's test (Egger et al., 1997) for funnel plot asymmetry, and Trim and Fill analyses (Duval \& Tweedie, 2000). We also conducted an exploratory p-curve analyses on the $p$ values of the $Z$ tests (SMD/SE), using the "dmetar" package (see supplementary analyses for p-curve figure). P-curve with a right skew (e.g., larger distribution of $p \mathrm{~s}<.01-.025)$ is indicative of a likely "true" effect when the distribution of $p$ values is uniformly distributed under the null hypothesis. If there is a left skew (e.g., greater distribution of $p$ values between .025 and .050 ), this is indicative of selective reporting. Evidential value is demonstrated using the continuous and half-tests of the $p p$ values (Simonsohn et al., 2015).

The meta-analysis was performed using R (R Team). Datasets and analysis script are available on OSF. Some papers reported multiple studies (e.g., Hardin et al., 2007; Padmanabhan et al., 2011; Scheres et al., 2001; Sinopoli et al., 2011), so that the primary analysis included 80 effect sizes. The degree of heterogeneity was assessed using $I^{2}$.
We used the following cut-offs for heterogeneity: $<25 \%$ low, $25 \%-50 \%$ modest, and $>50 \%$ high (Higgins et al., 2003). In our preregistration we stated that we would also examine proactive control; however, very few papers alluded to or measured proactive control, relative to reactive control. Therefore, we were unable to follow this up.

\section{Results}

\section{Study characteristics}

The majority of studies employed a within-subject (repeated measures) design, in which participants completed the measure of IC under both reward and nonreward conditions (e.g., Charles-Walsh et al., 2016; Marini et al., 2015; Scheres et al., 2001). We also identified four studies that used a between-subjects design, in which participants were randomly allocated to either the reward or non-reward condition (e.g., Huguet et al., 2004; Kohls et al., 2009; Marx et al., 2013). A number of studies examined the effect of reward on IC in clinical populations, for example, ADHD, SUD, and mental health (Byrne \& Worthy, 2019; Hardin et al., 2007; Miyasaka \& Nomura, 2019).

Of the studies included, the majority $(78.75 \%)$ used monetary rewards (both hypothetical and real; for example, Poulton et al., 2016; Williams et al., 2018), a small number (17.50\%) used "points" as rewards (e.g., Miyasaka \& Nomura, 2019), and 3.75\% used social rewards (e.g., Kohls et al., 2009). IC was measured using a variety of tasks. Of the 80 effect sizes, $N=19(23.75 \%)$ were measured using GNG; $N=16(20.00 \%)$ using SST; $N=13$ $(16.25 \%)$ using Flanker; $N=18(22.50 \%)$ using Antisaccade; $N=11(13.75 \%)$ using Stroop; and $N=3(3.75 \%)$ Simon task.

\section{Primary hypothesis: the effect of reward on IC}

Our main analysis consisted of 80 effect sizes (Figure 2). There was a small but statistically significant effect of the presence of reward improving IC (SMD $=0.429,95 \%$ $\left.\mathrm{CI}=[0.288,0.570], Z=5.97, p<.001, I^{2}=96.7 \%\right)$. Two studies had a $Z$ score \pm 3.30 and were removed, which did not substantially influence the effect size $(\mathrm{SMD}=.438$, $\left.95 \% \mathrm{CI}=[0.319,0.557], \mathrm{Z}=7.20, p<.001, I^{2}=95.2 \%\right) . \mathrm{A}$ leave-one-out analysis demonstrated limited variability in the effect size (min $\mathrm{SMD}=0.413$, $\max \mathrm{SMD}=0.453$ : all model $p$ s $<.001)$. Trim and Fill analyses did not impute any studies, but Egger's test of funnel plot asymmetry was significant $(Z=2.339, p=.019$ : see Figure 3 for funnel plot). Exploratory p-curve analyses demonstrated evidential value (full-curve $Z=-23.98, p<.001$ and half-curve $Z=-20.10, p<.001)$. Sensitivity analyses demonstrated that the effect size was $\mathrm{SMD}=0.297,95 \% \mathrm{CI}=[0.194$, $0.400]$ if the within-subjects correlation was imputed as 


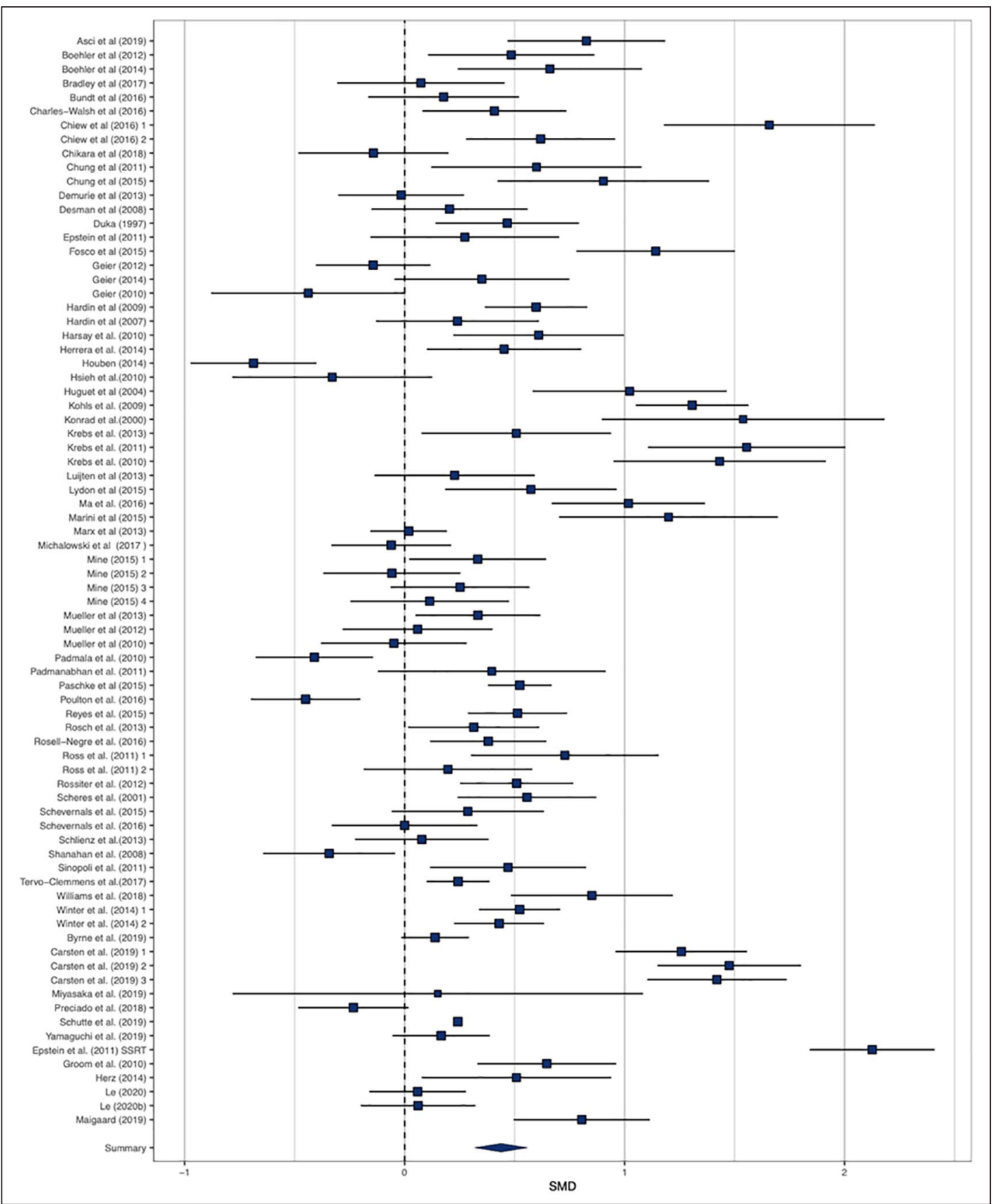

Figure 2. Forest plot of effect sizes for rewarded versus non-rewarded inhibitory control.

$r=.50$, and $\mathrm{SMD}=0.715,95 \% \mathrm{CI}=[0.522,0.907]$ if the correlation was imputed as $r=.90$. Overall, there was a small, significant effect of reward on IC, which was robust to outliers and influential cases.

\section{Potential moderators of the effect of reward on IC}

Task type. Using data with outliers removed we conducted a-priori moderation on task type. There was a significant moderation effect, $\chi^{2}(5)=16.79, p=.005$. There was a significant effect of reward all tasks: GNG task $(k=18$ : $\mathrm{SMD}=0.300,95 \% \mathrm{CI}=[0.127,0.472], Z=3.407, p<.001$, $\left.I^{2}=91.25 \%\right) ; \mathrm{SST}(k=16: \mathrm{SMD}=0.410,95 \% \mathrm{CI}=[0.050$, $\left.0.770], Z=2.233, p=.026, I^{2}=95.97 \%\right)$; Flanker task $(k=13: \mathrm{SMD}=0.407,95 \% \mathrm{CI}=[0.130,0.685], Z=2.877$, $\left.p=.004, I^{2}=90.56 \%\right)$; Simon task $(k=3: \mathrm{SMD}=0.502$, $\left.95 \% \mathrm{CI}=[0.126,0.878], Z=2.614, p=.009, I^{2}=69.81 \%\right)$; Anti-saccade task $(k=18: \mathrm{SMD}=0.286,95 \% \mathrm{CI}=[0.128$, 0.443], $Z=3.554, p<.001, I^{2}=78.09 \%$ ); and Stroop task $(k=10: \mathrm{SMD}=1.029,95 \% \mathrm{CI}=[0.728,1.328], Z=6.711$, 


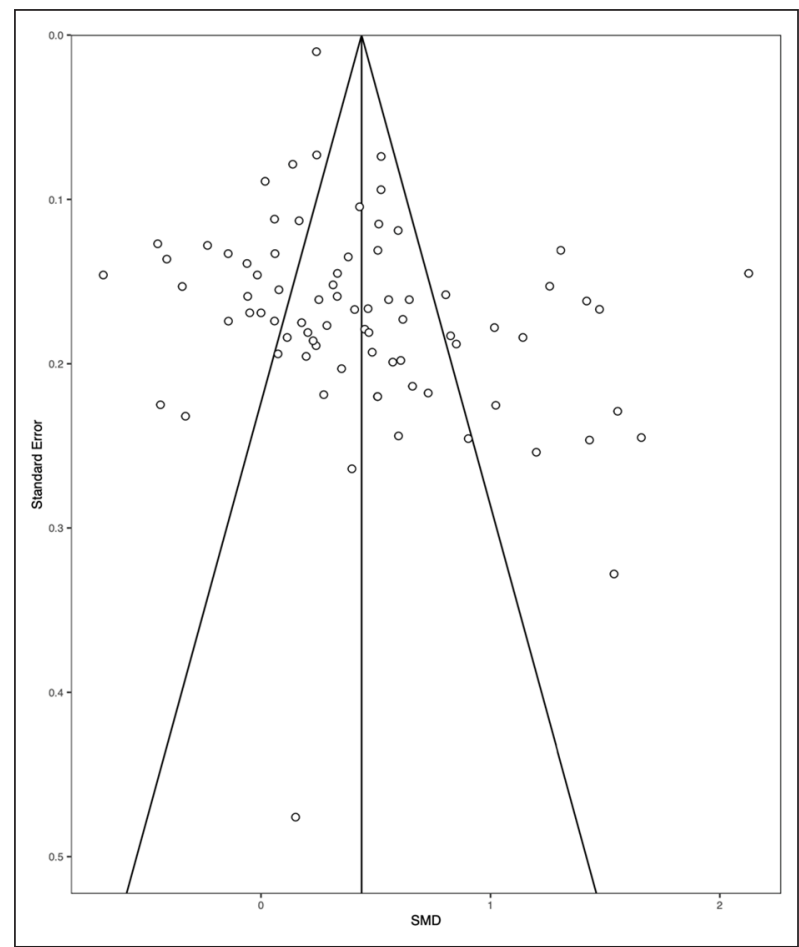

Figure 3. Funnel plot of the effect sizes plotted against the standard error in the meta-analysis.

$p<.001, I^{2}=86.36 \%$ ). The moderation effect was likely driven by the large effect sizes in Stroop tasks. Removal of the Stroop tasks from analyses made the moderator effect non-significant, $\chi^{2}(4)=0.986, p=.912$. Notably, analysing the tasks separately did not substantially reduce the heterogeneity across effect sizes.

Age. We conducted exploratory moderation analyses on age. There were $k=28$ effects from child samples $(\mathrm{SMD}=0.515,95 \% \mathrm{CI}=[0.315,0.714], Z=5.053, p<.001$, $\left.I^{2}=92.18 \%\right)$ and $k=50$ adult samples $(\mathrm{SMD}=0.396,95 \%$ $\left.\mathrm{CI}=[0.247,0.544], Z=5.217, p<.001, I^{2}=95.22 \%\right)$. There was no evidence of moderation, $\chi^{2}(1)=0.877, p=.349$.

Reward type. We conducted exploratory moderation analysis on reward type. There were $k=62$ effects using monetary reward $(\mathrm{SMD}=0.392,95 \% \mathrm{CI}=[0.266,0.518]$, $\left.Z=6.093, p<.001, I^{2}=94.68 \%\right), k=13$ effects using hypothetical "points" $(\mathrm{SMD}=0.586,95 \% \mathrm{CI}=[0.220,0.952]$, $\left.Z=3.138, p=.002, I^{2}=93.02 \%\right)$, and $k=3$ effects using "other" rewards $(\mathrm{SMD}=0.747,95 \% \mathrm{CI}=[0.208,1.287]$, $\left.Z=2.716, p=.007, I^{2}=94.79 \%\right)$. There was no evidence of moderation, $\chi^{2}(2)=2.863, p=.239$. Again, there was limited evidence that these moderator analyses reduced heterogeneity in the effect sizes.

Clinical samples. We conducted exploratory moderation analysis on clinical samples (vs "healthy controls"). There was no evidence of moderation, $\chi^{2}(1)=2.179, p=.140$. When examining ADHD samples versus healthy controls, there was no evidence of moderation, $\chi^{2}(1)=0.210$, $p=.646$. Similarly, when examining SUD samples versus healthy controls, there was no evidence of moderation, $\chi^{2}(1)=0.609, p=.435$.

Supplementary analyses: statistical power of included studies. Based on the pooled effect size of $\mathrm{SMD}=0.429$, a within-subjects comparison would require 35 participants to detect this effect (one-tailed, $1-\beta=.80, \mathrm{a}=.05$ ). Of the included studies $46(57.5 \%)$ had a large enough sample size to reliably detect this effect.

\section{Discussion}

The current meta-analyses demonstrated that the prospect of reward can improve IC. The overall effect size was small-to-moderate, with considerable heterogeneity across the studies. Analyses indicated the effect of reward on IC was not moderated by clinical sample or type of reward used. Task type was a significant moderator of the effect of reward on IC, as the effect size was considerably larger in studies which utilised a Stroop task. The heterogeneity was not explained by any of our moderator variables.

The effect of reward on IC was consistent with recent hypotheses from theoretical models and research on healthy populations, suggesting that rewards can improve momentary IC. Specifically, we find support for valuebased models (Berkman et al., 2017) in which reward appears to increase the value for a given behaviour (IC), increasing the "gain" compared with the "cost" of inhibition (Duckworth et al., 2016, 2018). The findings also support dual-process models (Evans, 2008), in which the prospect of a reward appears to improve the slower deliberate reflective systems, linked to executive control. These findings are also in line with similar meta-analyses (Jones et al., 2018), providing support for theoretical models which suggest that IC is a transient variable, which is sensitive to the internal and external factors (Jones et al., 2013; Keren \& Schul, 2009).

The variability in effect sizes was not explained by clinical diagnoses in our data. This is surprising as the main clinical populations sampled were individuals with ADHD (Demurie et al., 2016; Desman et al., 2008; Ma et al., 2016) and SUD (Charles-Walsh et al., 2016; Chung et al., 2011). Both disorders are characterised by disrupted reward processing (García-García et al., 2014; Tenenbaum et al., 2018), and with this particular sensitivity to rewarding stimuli, we may have expected an enhanced effect of reward on IC for these sub-groups. In the case of SUD populations, the lack of effect of reward may be due to the severity of the condition, for example, harmful use or dependency (Byrne \& Worthy, 2019), yet we did not have enough data to reliably investigate any differences by 
clinical diagnosis. Similarly, there was no evidence that the pooled effects were moderated by age of the participants, which may be surprising given IC improves with age into adulthood (Davis et al., 2003; Kray et al., 2020; Macdonald et al., 2014).

The effect of reward was significantly moderated by task type, with seemingly larger effects in the Stroop task. Nevertheless, reward does not appear to have a consistent effect across separate inhibitory modalities. Complex measures of IC such as the Flanker require constant monitoring and updating of rules, further complicated by manipulations of reward, requiring enhanced top-down control leading to increased working memory demand (Garon et al., 2008). IC is dependent upon the Working Memory Capacity (WMC; Burnham et al., 2014; Vandierendonck, 2014), allowing maintenance of task goals (Munakata et al., 2011), with poorer WMC and increased WMC load impairing IC (Burnham et al., 2014; Kane \& Engle, 2000; Unsworth et al., 2004).

A potential mechanism by which reward improves IC may be through attentional processes. Reward may increase the detection of the inhibitory signal (particularly when the inhibitory and reward signal are the same; see Schevernels et al., 2015), leading to improved stimulus detection and reactive control (van den Berg et al., 2014; Wang et al., 2018); however, future research is needed to clarify these predictions. Research should also attempt to elucidate any individual differences which might serve to moderate the effects, for example, reward sensitivity (Capa \& Bouquet, 2018). Unfortunately, we could not examine the effect of reward on reactive and proactive control due to lack of data available, therefore conclusions cannot be drawn about the mechanism that reward affects IC, for example, reactive or proactive control. Future studies should attempt to disentangle these effects to improve our overall understanding of IC (Verbruggen et al., 2014).

Given that reward appears to significantly improve IC, there are implications for the development of self-control interventions which focus on IC (e.g., inhibitory control training [ICT]). Recent meta-analyses suggest that ICT leads to short-term changes in behaviour (Allom et al., 2016; Jones et al., 2016). Reward may be used to increase the value of health-related cues (e.g., healthy foods) or devalue unhealthy behaviour-related cues (e.g., unhealthy foods) within these tasks. The opportunity to gain rewards for avoiding health risk and actively engaging in health promotion behaviour (Higgins et al., 2004; Vlaev et al., 2019) may serve to improve associative learning and strengthen the intervention effects (Schultz, 2002; Zhang et al., 2014).

We found evidence of bias in the literature following Egger's test. While this suggests that publication bias is having a persuasive influence on the literature, researchers have suggested that such analysis is interpreted with caution, particularly when there is heterogeneity in the dataset
(Shi \& Lin, 2019). As such, researchers should endeavour to preregister their work to provide increased transparency. There should be particular focus on replication attempts, as meta-analytic effect sizes are proposed to be nearly three times as large as registered replications (Kvarven et al., 2019).

We acknowledge the following limitations. First, we did not assess neuropsychological outcomes (such as event-related potentials) which were presented in some of the research (Chung et al., 2011; Schevernels et al., 2015). These outcomes may be more sensitive than behavioural measures and provide a deeper understanding of the role of reward on IC, allowing the formation of a more comprehensive mechanism. Second, reward was only assessed in the form of extrinsic motivation, for example, in the presence of a reward specific cue. As such, future work should endeavour to examine the work of intrinsically rewarding appetitive stimuli to examine whether similar effects on IC are observed as described here. There is a large amount of variability in the clinical populations in the current metaanalysis, which may vary in their responsiveness to reward, making it difficult to draw conclusions on the moderating effect of clinical diagnosis on reward and IC. Therefore, interpretation of the (lack of) findings should remain cautious. Future research should seek to look at specific populations in respect to this, to better our understanding of the potential moderating role of given clinical diagnoses.

To conclude, the meta-analysis presented here suggests that the presence of reward can improve IC. Despite previous literature suggesting that individuals diagnosed with ADHD or SUDs have increased reward sensitivity, suggested a moderating role of diagnosis, we found no such evidence to support this. With reward significantly improving IC, this provides a potential avenue of treatment development for ICT, specifically producing a more prolonged behavioural change.

\section{Author contributions}

S.B. and A.J. devised the research; S.B. wrote the pre-registration, which was reviewed and revised by G.K. and A.J.; S.B. and G.K. conducted the systematic review and data extraction; S.B. conducted the analyses, supervised by A.J.; and S.B. drafted the initial manuscript. All authors provided feedback on the manuscript drafts.

\section{Declaration of conflicting interests}

The author(s) declared no potential conflicts of interest with respect to the research, authorship, and/or publication of this article.

\section{Funding}

The author(s) disclosed receipt of the following financial support for the research, authorship, and/or publication of this article: This work was supported by a research studentship from Alcohol Change (Grant No. RS 17/01). 


\section{ORCID iD}

Sam Burton (iD https://orcid.org/0000-0003-3823-3275

\section{Supplementary material}

The supplementary material is available at qjep.sagepub.com.

\section{References}

Allom, V., Mullan, B., \& Hagger, M. (2016). Does inhibitory control training improve health behaviour? A meta-analysis. Health Psychology Review, 10(2), 168-186.

Anzman-Frasca, S., Francis, L. A., \& Birch, L. L. (2015). Inhibitory control is associated with psychosocial, cognitive, and weight outcomes in a longitudinal sample of girls. Translational Issues in Psychological Science, 1(3), 203216. https://doi.org/10.1037/tps0000028

Aron, A. R. (2011). From reactive to proactive and selective control: Developing a richer model for stopping inappropriate responses. Biological Psychiatry, 69(12), e55-e68. https:// doi.org/10.1016/j.biopsych.2010.07.024

Asci, O., Braem, S., Park, H. R. P., Boehler, C. N., \& Krebs, R. M. (2019). Neural correlates of reward-related response tendencies in an equiprobable Go/NoGo task. Cognitive, Affective, \& Behavioral Neuroscience. https://doi.org/10.3758/s 13415-019-00692-5

Band, G. P., van der Molen, M. W., \& Logan, G. D. (2003). Horse-race model simulations of the stop-signal procedure. Acta Psychologica, 112(2), 105-142.

Baumeister, R. F. (2014). Self-regulation, ego depletion, and inhibition. Neuropsychologia, 65, 313-319.

Berkman, E. T., Hutcherson, C. A., Livingston, J. L., Kahn, L. E., \& Inzlicht, M. (2017). Self-control as value-based choice. Current Directions in Psychological Science, 26(5), 422-428.

Bickel, W. K., Jarmolowicz, D. P., Mueller, E. T., Gatchalian, K. M., \& McClure, S. M. (2012). Are executive function and impulsivity antipodes? A conceptual reconstruction with special reference to addiction. Psychopharmacology, 221(3), 361-387.

Blanco-Gómez, A., Ferré, N., Luque, V., Cardona, M., GispertLlauradó, M., Escribano, J., . . Canals-Sans, J. (2015). Being overweight or obese is associated with inhibition control in children from six to ten years of age. Acta Paediatrica, 104(6), 619-625. https://doi.org/10.1111/apa.12976

Boehler, C. N., Schevernels, H., Hopf, J.-M., Stoppel, C. M., \& Krebs, R. M. (2014). Reward prospect rapidly speeds up response inhibition via reactive control. Cognitive, Affective, \& Behavioral Neuroscience, 14(2), 593-609. https://doi. org/10.3758/s13415-014-0251-5

Braver, T. S., Gray, J. R., \& Burgess, G. C. (2007). Explaining the many varieties of working memory variation: Dual mechanisms of cognitive control. In C. Jarrold, J. Towse, A. Miyake, A. Conway, \& M. Kane (Eds.), Variation in working memory (pp. 76-106). Oxford University Press.

Burnham, B. R., Sabia, M., \& Langan, C. (2014). Components of working memory and visual selective attention. Journal of Experimental Psychology: Human Perception and Performance, 40(1), 391-403.

Byrne, K. A., \& Worthy, D. A. (2019). Examining the link between reward and response inhibition in individuals with substance abuse tendencies. Drug and Alcohol Dependence, 194, 518525. https://doi.org/10.1016/j.drugalcdep.2018.11.014
Capa, R. L., \& Bouquet, C. A. (2018). Individual differences in reward sensitivity modulate the distinctive effects of conscious and unconscious rewards on executive performance. Frontiers in Psychology, 9, Article 148.

Caspi, A., Houts, R. M., Belsky, D. W., Harrington, H., Hogan, S., Ramrakha, S., . . . Moffitt, T. E. (2016). Childhood forecasting of a small segment of the population with large economic burden. Nature Human Behaviour, 1, Article 0005. https://doi.org/10.1038/s41562-016-0005

Charles-Walsh, K., Upton, D. J., \& Hester, R. (2016). Examining the interaction between cognitive control and reward sensitivity in substance use dependence. Drug and Alcohol Dependence, 166, 235-242.

Chiew, K. S., Stanek, J. K., \& Adcock, R. A. (2016). Reward anticipation dynamics during cognitive control and episodic encoding: Implications for dopamine. Frontiers in Human Neuroscience, 10, Article 555. https://doi.org/10.3389/ fnhum.2016.00555

Chung, T., Geier, C., Luna, B., Pajtek, S., Terwilliger, R., Thatcher, D., \& Clark, D. B. (2011). Enhancing response inhibition by incentive: Comparison of adolescents with and without substance use disorder. Drug and Alcohol Dependence, 115(1), 43-50. https://doi.org/10.1016/j. drugalcdep.2010.10.017

Cumpston, M., Li, T., Page, M. J., Chandler, J., Welch, V. A., Higgins, J. P., \& Thomas, J. (2019). Updated guidance for trusted systematic reviews: A new edition of the Cochrane Handbook for Systematic Reviews of Interventions. Cochrane Database of Systematic Reviews, 10, Article ED000142.

Davis, E. P., Bruce, J., Snyder, K., \& Nelson, C. A. (2003). The X-trials: Neural correlates of an inhibitory control task in children and adults. Journal of Cognitive Neuroscience, 15(3), 432-443.

Demurie, E., Roeyers, H., Wiersema, J. R., \& Sonuga-Barke, E. (2016). No evidence for inhibitory deficits or altered reward processing in ADHD: Data from a new integrated monetary incentive delay Go/No-Go task. Journal of Attention Disorders, 20(4), 353-367. https://doi. org/10.1177/1087054712473179

Desman, C., Petermann, F., \& Hampel, P. (2008). Deficit in response inhibition in children with attention deficit/hyperactivity disorder (ADHD): Impact of motivation? Child Neuropsychology, 14(6), 483-503.

Diamond, A. (2013). Executive functions. Annual Review of Psychology, 64, 135-168.

Duckworth, A. L., Gendler, T. S., \& Gross, J. J. (2016). Situational strategies for self-control. Perspectives on Psychological Science, 11(1), 35-55. https://doi.org/10.1177/174569161 5623247

Duckworth, A. L., Milkman, K. L., \& Laibson, D. (2018). Beyond willpower: Strategies for reducing failures of selfcontrol. Psychological Science in the Public Interest, 19(3), 102-129. https://doi.org/10.1177/1529100618821893

Duval, S., \& Tweedie, R. (2000). Trim and fill: A simple funnelplot-based method of testing and adjusting for publication bias in meta-analysis. Biometrics, 56(2), 455-463.

Eagle, D. M., Bari, A., \& Robbins, T. W. (2008). The neuropsychopharmacology of action inhibition: Cross-species translation of the stop-signal and go/no-go tasks. Psychopharmacology, 199(3), 439-456. https://doi.org/10.1007/ s00213-008-1127-6 
Egger, M., Smith, G. D., Schneider, M., \& Minder, C. (1997). Bias in meta-analysis detected by a simple, graphical test. BMJ (Clinical Research Edition), 315(7109), 629-634.

Eriksen, B. A., \& Eriksen, C. W. (1974). Effects of noise letters upon the identification of a target letter in a nonsearch task. Perception \& Psychophysics, 16(1), 143-149.

Evans, J. S. B. (2008). Dual-processing accounts of reasoning, judgment, and social cognition. Annual Review of Psychology, 59, 255-278.

García-García, I., Horstmann, A., Jurado, M. A., Garolera, M., Chaudhry, S. J., Margulies, D. S., . . Neumann, J. (2014). Reward processing in obesity, substance addiction and nonsubstance addiction. Obesity Reviews, 15(11), 853-869.

Garon, N., Bryson, S. E., \& Smith, I. M. (2008). Executive function in preschoolers: A review using an integrative framework. Psychological Bulletin, 134(1), 31-60.

Geier, C. F., \& Luna, B. (2012). Developmental effects of incentives on response inhibition. Child Development, 83(4), 1262-1274. https://doi.org/10.1111/j.1467-8624.2012.01771.x

Hardin, M. G., Schroth, E., Pine, D. S., \& Ernst, M. (2007). Incentive-related modulation of cognitive control in healthy, anxious, and depressed adolescents: Development and psychopathology related differences. Journal of Child Psychology and Psychiatry, 48(5), 446-454. https://doi. org/10.1111/j.1469-7610.2006.01722.x

Higgins, J. P. T., Thompson, S. G., Deeks, J. J., \& Altman, D. G. (2003). Measuring inconsistency in meta-analyses. BMJ (Clinical Research Edition), 327(7414), 557-560. https:// doi.org/10.1136/bmj.327.7414.557

Higgins, S. T., Heil, S. H., \& Lussier, J. P. (2004). Clinical implications of reinforcement as a determinant of substance use disorders. Annual Review of Psychology, 55, 431-461.

Hofmann, W., Luhmann, M., Fisher, R. R., Vohs, K. D., \& Baumeister, R. F. (2014). Yes, but are they happy? Effects of trait self-control on affective well-being and life satisfaction. Journal of Personality, 82(4), 265-277. https://doi. org/10.1111/jopy.12050

Hofmann, W., Schmeichel, B. J., \& Baddeley, A. D. (2012). Executive functions and self-regulation. Trends in Cognitive Sciences, 16(3), 174-180. https://doi.org/10.1016/j.tics. 2012.01.006

Huguet, P., Dumas, F., \& Monteil, J. M. (2004). Competing for a desired reward in the Stroop task: When attentional control is unconscious but effective versus conscious but ineffective. Canadian Journal of Experimental Psychology, 58(3), 153-167. https://doi.org/10.1037/h0087441

Jimura, K., Locke, H. S., \& Braver, T. S. (2010). Prefrontal cortex mediation of cognitive enhancement in rewarding motivational contexts. Proceedings of the National Academy of Sciences of the United States of America, 107(19), 88718876. https://doi.org/10.1073/pnas.1002007107

Jones, A., Christiansen, P., Nederkoorn, C., Houben, K., \& Field, M. (2013). Fluctuating disinhibition: Implications for the understanding and treatment of alcohol and other substance use disorders. Frontiers in Psychiatry, 4, Article 140. https://doi.org/10.3389/fpsyt.2013.00140

Jones, A., Di Lemma, L. C., Robinson, E., Christiansen, P., Nolan, S., Tudur-Smith, C., \& Field, M. (2016). Inhibitory control training for appetitive behaviour change: A metaanalytic investigation of mechanisms of action and moderators of effectiveness. Appetite, 97, 16-28.
Jones, A., Robinson, E., Duckworth, J., Kersbergen, I., Clarke, N., \& Field, M. (2018). The effects of exposure to appetitive cues on inhibitory control: A meta-analytic investigation. Appetite, 128, 271-282.

Kane, M. J., \& Engle, R. W. (2000). Working-memory capacity, proactive interference, and divided attention: Limits on long-term memory retrieval. Journal of Experimental Psychology: Learning, Memory, and Cognition, 26(2), 336-358.

Keren, G., \& Schul, Y. (2009). Two is not always better than one: A critical evaluation of two-system theories. Perspectives on Psychological Science, 4(6), 533-550. https://doi. org/10.1111/j.1745-6924.2009.01164.x

Khoury, B., Sharma, M., Rush, S. E., \& Fournier, C. (2015). Mindfulness-based stress reduction for healthy individuals: A meta-analysis. Journal of Psychosomatic Research, 78(6), 519-528. https://doi.org/10.1016/j.jpsychores.2015.03.009

Kohls, G., Peltzer, J., Herpertz-Dahlmann, B., \& Konrad, K. (2009). Differential effects of social and non-social reward on response inhibition in children and adolescents. Developmental Science, 12(4), 614-625. https://doi. org/10.1111/j.1467-7687.2009.00816.x

Kray, J., Ritter, H., \& Mueller, L. (2020). The interplay between cognitive control and emotional processing in children and adolescents. Journal of Experimental Child Psychology, 193, Article 104795.

Kvarven, A., Strømland, E., \& Johannesson, M. (2020). Comparing meta-analyses and preregistered multiple-laboratory replication projects. Nature Human Behaviour, 4, 423-434.

Logan, G. D., Cowan, W. B., \& Davis, K. A. (1984). On the ability to inhibit simple and choice reaction time responses: A model and a method. Journal of Experimental Psychology: Human Perception and Performance, 10(2), 276-291. https://doi.org/10.1037//0096-1523.10.2.276

Ma, I., van Holstein, M., Mies, G. W., Mennes, M., Buitelaar, J., Cools, R., . . Scheres, A. (2016). Ventral striatal hyperconnectivity during rewarded interference control in adolescents with ADHD. Cortex, 82, 225-236. https://doi. org/10.1016/j.cortex.2016.05.021

Macdonald, J. A., Beauchamp, M. H., Crigan, J. A., \& Anderson, P. J. (2014). Age-related differences in inhibitory control in the early school years. Child Neuropsychology, 20(5), 509-526.

Marini, F., van den Berg, B., \& Woldorff, M. G. (2015). Rewardprospect interacts with trial-by-trial preparation for potential distraction. Visual Cognition, 23(1-2), 313-335. https:// doi.org/10.1080/13506285.2015.1023387

Marx, I., Höpcke, C., Berger, C., Wandschneider, R., \& Herpertz, S. C. (2013). The impact of financial reward contingencies on cognitive function profiles in adult ADHD. PLOS ONE, 8(6), Article e67002. https://doi.org/10.1371/journal. pone. 0067002

Michałowski, J. M., Koziejowski, W., Droździel, D., Harciarek, M., \& Wypych, M. (2017). Error processing deficits in academic procrastinators anticipating monetary punishment in a go/no-go study. Personality and Individual Differences, 117, 198-204. https://doi.org/10.1016/j.paid. 2017.06.010

Miyake, A., \& Friedman, N. P. (2012). The nature and organization of individual differences in executive functions: Four general 
conclusions. Current Directions in Psychological Science, 21(1), 8-14. https://doi.org/10.1177/0963721411429458

Miyasaka, M., \& Nomura, M. (2019). Asymmetric developmental change regarding the effect of reward and punishment on response inhibition. Scientific Reports, 9(1), Article 12882. https://doi.org/10.1038/s41598-019-49037-9

Munakata, Y., Herd, S. A., Chatham, C. H., Depue, B. E., Banich, M. T., \& O'Reilly, R. C. (2011). A unified framework for inhibitory control. Trends in Cognitive Sciences, 15(10), 453-459.

Padmanabhan, A., Geier, C. F., Ordaz, S. J., Teslovich, T., \& Luna, B. (2011). Developmental changes in brain function underlying the influence of reward processing on inhibitory control. Developmental Cognitive Neuroscience, 1(4), $517-529$.

Paschke, L. M., Walter, H., Steimke, R., Ludwig, V. U., Gaschler, R., Schubert, T., \& Stelzel, C. (2015). Motivation by potential gains and losses affects control processes via different mechanisms in the attentional network. NeuroImage, 111, 549-561. https://doi.org/10.1016/j.neuroimage.2015.02.047

Polderman, T. J. C., de Geus, E. J. C., Hoekstra, R. A., Bartels, M., van Leeuwen, M., Verhulst, F. C., . . . Boomsma, D. I. (2009). Attention problems, inhibitory control, and intelligence index overlapping genetic factors: A study in 9-, 12-, and 18-year-old twins. Neuropsychology, 23(3), 381-391. https://doi.org/10.1037/a0014915

Poulton, A., Mackenzie, C., Harrington, K., Borg, S., \& Hester, R. (2016). Cognitive control over immediate reward in binge alcohol drinkers. Alcoholism: Clinical and Experimental Research, 40(2), 429-437. https://doi.org/https://doi. org/10.1111/acer.12968

Prinzmetal, W., McCool, C., \& Park, S. (2005). Attention: reaction time and accuracy reveal different mechanisms. $J$ Exp Psychol Gen, 134(1), 73-92.

Rosell-Negre, P., Bustamante, J.-C., Fuentes-Claramonte, P., Costumero, V., Llopis-Llacer, J.-J., \& Barrós-Loscertales, A. (2016). Reward contingencies improve goal-directed behavior by enhancing posterior brain attentional regions and increasing corticostriatal connectivity in cocaine addicts. PLOS ONE, 11(12), Article e0167400. https://doi. org/10.1371/journal.pone.0167400

Rosenthal, R. (1991). Meta-analytic procedures for social research (Rev. ed.). SAGE.

Rubio, G., Jiménez, M., Rodríguez-Jiménez, R., Martínez, I., Ávila, C., Ferre, F., Jiménez-Arriero, M. A., . . . Palomo, T. (2008). The role of behavioral impulsivity in the development of alcohol dependence: A 4-year follow-up study. Alcoholism: Clinical and Experimental Research, 32(9), 1681-1687.

Scheres, A., Oosterlaan, J., \& Sergeant, J. A. (2001). Response inhibition in children with DSM-IV subtypes of AD/HD and related disruptive disorders: The role of reward. Child Neuropsychology, 7(3), 172-189. https://doi.org/10.1076/ chin.7.3.172.8746

Schevernels, H., Bombeke, K., Krebs, R. M., \& Boehler, C. N. (2016). Preparing for (valenced) action: The role of differential effort in the orthogonalized go/no-go task. Psychophysiology, 53(2), 186-197. https://doi.org/10.1111/ psyp. 12558
Schevernels, H., Bombeke, K., Van der Borght, L., Hopf, J.-M., Krebs, R. M., \& Boehler, C. N. (2015). Electrophysiological evidence for the involvement of proactive and reactive control in a rewarded stop-signal task. NeuroImage, 121, 115-125.

Schultz, W. (2002). Getting formal with dopamine and reward. Neuron, 36(2), 241-263. https://doi.org/10.1016/s08966273(02)00967-4

Shanahan, M. A., Pennington, B. F., \& Willcutt, E. W. (2008). Do motivational incentives reduce the inhibition deficit in ADHD? Developmental Neuropsychology, 33(2), 137-159.

Shi, L., \& Lin, L. (2019). The trim-and-fill method for publication bias: Practical guidelines and recommendations based on a large database of meta-analyses. Medicine, 98(23), Article e15987.

Simonsohn, U., Simmons, J. P., \& Nelson, L. D. (2015). Better P-curves: Making P-curve analysis more robust to errors, fraud, and ambitious P-hacking, a Reply to Ulrich and Miller (2015). Journal of Experimental Psychology: General, 144(6), 1146-1152.

Sinopoli, K. J., Schachar, R., \& Dennis, M. (2011). Reward improves cancellation and restraint inhibition across childhood and adolescence. Developmental Psychology, 47(5), 1479-1489.

Snyder, H. R., Miyake, A., \& Hankin, B. L. (2015). Advancing understanding of executive function impairments and psychopathology: Bridging the gap between clinical and cognitive approaches. Frontiers in Psychology, 6, Article 328. https://doi.org/10.3389/fpsyg.2015.00328

Stroop, J. R. (1935). Studies of interference in serial verbal reactions. Journal of Experimental Psychology, 18(6), 643-662.

Tenenbaum, R. B., Musser, E. D., Raiker, J. S., Coles, E. K., Gnagy, E. M., \& Pelham, W. E. (2018). Specificity of reward sensitivity and parasympathetic-based regulation among children with attention-deficit/hyperactivity and disruptive behavior disorders. Journal of Abnormal Child Psychology, 46(5), 965-977.

Umemoto, A., \& Holroyd, C. B. (2015). Task-specific effects of reward on task switching. Psychological Research, 79(4), 698-707. https://doi.org/10.1007/s00426-014-0595-z

Unsworth, N., Schrock, J. C., \& Engle, R. W. (2004). Working memory capacity and the antisaccade task: Individual differences in voluntary saccade control. Journal of Experimental Psychology: Learning, Memory, and Cognition, 30(6), 1302-1321.

van den Berg, B., Krebs, R. M., Lorist, M. M., \& Woldorff, M. G. (2014). Utilization of reward-prospect enhances preparatory attention and reduces stimulus conflict. Cognitive, Affective, \& Behavioral Neuroscience, 14(2), 561-577.

Vandierendonck, A. (2014). Symbiosis of executive and selective attention in working memory. Frontiers in Human Neuroscience, 8, Article 588.

Vazsonyi, A. T., Mikuška, J., \& Kelley, E. L. (2017). It's time: A meta-analysis on the self-control-deviance link. Journal of Criminal Justice, 48, 48-63. https://doi.org/10.1016/j. jcrimjus.2016.10.001

Verbruggen, F., McLaren, I. P., \& Chambers, C. D. (2014). Banishing the control homunculi in studies of action control and behavior change. Perspectives on Psychological Science, 9(5), 497-524. 
Vlaev, I., King, D., Darzi, A., \& Dolan, P. (2019). Changing health behaviors using financial incentives: A review from behavioral economics. BMC Public Health, 19(1), Article 1059.

Wang, L., Li, S., Zhou, X., \& Theeuwes, J. (2018). Stimuli that signal the availability of reward break into attentional focus. Vision Research, 144, 20-28. https://doi.org/10.1016/j.visres.2017.10.008

Williams, R. S., Kudus, F., Dyson, B. J., \& Spaniol, J. (2018). Transient and sustained incentive effects on electrophysiological indices of cognitive control in younger and older adults. Cognitive, Affective, \& Behavioral Neuroscience, 18(2), 313-330. https://doi.org/10.3758/s13415-018-0571-y
Yamaguchi, M., \& Nishimura, A. (2019). Modulating proactive cognitive control by reward: Differential anticipatory effects of performance-contingent and non-contingent rewards. Psychological Research, 83(2), 258-274. https:// doi.org/10.1007/s00426-018-1027-2

Young, M. E., Sutherland, S. C., \& McCoy, A. W. (2018). Optimal go/no-go ratios to maximize false alarms. Behavior Research Methods, 50(3), 1020-1029. https://doi. org/10.3758/s13428-017-0923-5

Zhang, Z., Manson, K. F., Schiller, D., \& Levy, I. (2014). Impaired associative learning with food rewards in obese women. Current Biology, 24(15), 1731-1736. https://doi. org/10.1016/j.cub.2014.05.075 